\title{
Advertising in the USA Historical Utopia
}

\section{Clarence W Thomas*}

School of Mass Communications, Virginia Commonwealth University, USA

Historically, advertising content in the U.S. (particularly in the 1950s) has lacked sensitivity to, and awareness of, diversity in terms of the subject(s) portrayed and the potential audience. In essence, in advertising minorities (Black, Asian, Hispanic, Native American, etc.) did not exist. On rare occasion, when minorities did appear in ads, they were depicted in a negative, stereotypical way. For example, Blacks were often depicted in subservient roles such as Uncle Ben or Aunt Jemima. Hispanics might be depicted as banditos and Asian as slant eyed humorous or even threatening characters.

Advertising in the U.S. sought to create a white utopia where everything was fine and dandy. The white male was master of the house. However, this utopia was flawed by the gender stereotyping of the white female who was placed in the subservient role of the ideal happy home maker. She often wore a dress and pearls while serving milk and cookies to the children. Of course, dinner was always cooked and placed on the table at the same time each day.

In her book Controversies in Contemporary Advertising, Kim
Sheehanprovides discussion and analysis of several of the important topics and sub-topics of this major subject. Her book examines (but is not limited to) influences of stereotypes and taste, advertising and race, advertising and gender, and advertising and age/sexual orientation/ ability. Sheehan examines the range of stereotypes presented in advertising messages, the valence of stereotypes presented for a specific group, and the frequency of the portrayals of each stereotype.

Sheehan discusses the notions of marginalization and invisibility noting that minorities still tend to be underrepresented in advertising. In terms of gender stereotyping the notes that stereotypes are created by the continual extended exposure of consumers to patterns of imagery. As such, she goes on to examine role portrayals, beauty stereotypes, and decorative/sexual stereotypes as related to gender. Sheehan poses the proposition that until advertising agencies (which tend to be male and white in composition) are more diverse (as a work force) the potential for ads to put people down rather than lift them up still exist. Job well done!
*Corresponding author: Clarence W Thomas, Associate Professor, School of Mass Communications, Virginia Commonwealth University, USA, Tel: 804-8273772; E-mail: cwthomas@vcu.edu

Received December 10, 2013; Accepted December 23, 2013; Published December 24, 2013

Citation: Thomas CW (2013) Advertising in the USA Historical Utopia. J Mass Communicat Journalism 4: e149. doi:10.4172/2165-7912.1000e149

Copyright: (c) 2013 Thomas CW. This is an open-access article distributed under the terms of the Creative Commons Attribution License, which permits unrestricted use, distribution, and reproduction in any medium, provided the original author and source are credited. 